\title{
The Epidemiology of Left-Handedness in a Hospital Population
}

\author{
STEVEN D. STELLMAN, PhD, ERNST L. WYNDER, MD, DAVID J. DeROSE, MD,* \\ AND JOSHUA E. MUSCAT, MPH
}

\begin{abstract}
PURPOSE: We evaluated the association between left-handedness ( $\mathrm{LH})$ and age, education, cigaretre smoking, alcohol consumption, and disease status in a case-control study of 8801 hospitalized patients with cancer and those with other conditions.

METHODS: Subjects were interviewed in person using a structured questionnaire that contained detailed sections of lifestyle behaviors.

RESULTS: The overall prevalences of LH were $7.6 \%$ among men and $6.5 \%$ among women. Among both sexes $\mathrm{LH}$ declined with increasing age $(P<0.05)$. After adjustment for age, the following associations were observed. Men had a higher risk of LH than women. The prevalence of LH was lower in ever-married subjects compared with never-married subjects (odds ratio [OR] for men, 0.7; 95\% confidence intervals $[\mathrm{CI}], 0.5-0.9$; for women, $\mathrm{OR}, 0.5 ; 95 \% \mathrm{CI}, 0.3-0.9$ ). Among men, the prevalence of $\mathrm{LH}$ was not associated with race, years of education, smoking status, or levels of alcohol consumption. The risk of LH was elevated in men diagnosed with fractures as compared with all other male patients (OR, 2.4; 95\% CI, 1.3-6.7). Among women, LH was not associated with race, smoking, or hormonal and reproductive factors, but LH was more common among female high-school and college graduates and among self-reported alcoholics. The odds ratio of $\mathrm{LH}$ was significantly lower in women with bredat cancer $(\mathrm{OR}, 0.3 ; 95 \% \mathrm{CI}, 0.1-0.7)$.

CONCLUSIONS: The increased risk of serious injuries in $\mathrm{LH}$ is not a result of higher alcohol use. Handedness might be an important factor in the safe use of industrial equipment.

Ann Epidemiol 1997;7:167-17! (C) 1997 by Elsevier Science Inc.
\end{abstract}

KEY WORDS: Left-handedness, fractures, education, alcohol, breast cancer, case-control study

\section{INTRODUCTION}

The relationship between handedness and morbidity or mortality has been extensively examined in recent years. In several studies (1-6), left-handedness (LH) was associated with shorter life span or higher mortality rates as compared with right-handedness. It has been hypothesized that the survival differences for $\mathrm{LH}$ could reflect historical trends in social pressure on left-handed individuals to switch to the right-hand during early childhood, usually before the age of 8 years, or that left-handed individuals learn to use their right-hand over time (7-9). However, other data indicate that societal pressures do not account for the age-related mortality differences in handedness (5). Other studies of handedness found no differences in life span or mortality rates (10-16). One study that examined both age-related differences in handedness and patterns of switching the writing hand found a decline in $\mathrm{LH}$ with age, but this trend was only partially accounted for by switching hands (17). If handedness is related to selective morbidity and mortality, it is worthwhile determining whether left-handed persons

Address reprint requests to: Joshua E. Muscat, American Health Foundation, 320 East 43rd Street, New York, NY 10017.

*Current address: Lifestyle Center of America, Route 2 Box 4001, Sulphur, OK 70386.

Received January 18, 1996; accepted November 25, 1996. differ from right-handed persons in regard to important lifestyle habits that are related to the risk of disease. In this study we examined the prevalence of LH by age, education, race, cigarette smoking, alcohol consumption, hormonal and reproductive factors, and disease category.

\section{MATERIALS AND METHODS}

The data are from a case-control study of smoking and tobacco-related cancers that was conducted between 1986 and 1990. The design of this study has been described elsewhere (18). Briefly, in participating hospitals we attempted to interview all incident cases of cancer of the lung, upper respiratory and upper digestive tracts, kidney, bladder, liver, and pancreas, as well as myocardial infarction in adults. Over $90 \%$ of subjects who were approached agreed to be interviewed. One control was matched to each case by age ( \pm 5 years), hospital, and date of admission ( \pm 2 months). Controls included patients with a variety of diagnoses unrelated to tobacco use. During the hospital stay, trained interviewers collected detailed information on smoking and other lifestyle variables and gathered diagnosis information from pathology reports and medical records. All cancers were confrrmed histologically.

Handedness is only one element of a constellation of 
TABLE 1. Prevalence of left-handedness among 8801 hospitalized patients by age and sex

\begin{tabular}{llllr}
\hline & \multicolumn{4}{c}{ No. with LH/total no. (\%) } \\
\cline { 2 - 5 } Age (years) & \multicolumn{2}{c}{ Men" $^{\prime}$} & \multicolumn{2}{c}{ Women" } \\
\hline$<44$ & $57 / 536$ & $(10.6)$ & $26 / 230$ & $(11.3)$ \\
$45-54$ & $114 / 1183$ & $(9.6)$ & $38 / 595$ & $(6.4)$ \\
$55-64$ & $172 / 2308$ & $(7.5)$ & $71 / 1070$ & $(6.6)$ \\
$65-74$ & $109 / 1661$ & $(6.6)$ & $52 / 963$ & $(5.4)$ \\
$75-84$ & $26 / 347$ & $(7.5)$ & $14 / 230$ & $(6.1)$ \\
Total & $478 / 6035$ & $(7.9)$ & $201 / 3088$ & $(6.5)$ \\
\hline
\end{tabular}

${ }^{a}$ Among men the age-related differences in prevalence of $\mathrm{LH}$ are significant $(P<0.01)$; among women these differences, were also significant $(P<0.05)$

traits known collectively as "lateral preference," which also includes foot, ear, and eye preferences. It is often measured as a continuous variable, using a validated scale (the Edinburgh Inventory) (19), which assigns to individuals a score between -1 (completely left-sided) and +1 (completely rightsided). The distribution of this score is highly skewed toward complete right-handedness, with left handers tending to spread out; many people are totally right-handed, but very few are totally left-handed or genuinely ambidextrous. Because handedness is the strongest of these (i.e., it tends to show the highest degree of single-sidedness in a given population), handedness is the best single measure of lateral preference. Thus handedness measured as a bilateral trait can adequately represent lateral preference. In this study, the question, "Are you right-handed or left-handed," was asked of all subjects. A total of 9123 interviews in which handedness was indicated were available for analysis. Of these subjects, 6035 (64.9\%) were male. We obtained information on hormonal and reproductive factors from a subset of 1011 women.

The association between handedness and disease or disease risk factors was assessed by $\chi^{2}$-square and stratified analysis. The odds ratio of $\mathrm{LH}$ was calculated by the MantelHaenszel odds ratio (OR) with adjustment for five age strata. The $95 \%$ confidence intervals $(\mathrm{Cl})$ were calculated by testhased methods.

\section{RESULTS}

\section{Effects of Demographic Factors}

Age and sex. The prevalences of $\mathrm{LH}$ were $7.9 \%$ among men and $6.5 \%$ among women. In both men and women, there was a decline in $\mathrm{LH}$ with advancing age (Table 1). The prevalence of LH decreased from $10.6 \%$ among men under 45 years of age to $6.6 \%$ among men $65-74$ years old, although the prevalence was slightly higher $(7.5 \%)$ among men aged $75-84$ years $(P<0.01)$. Among women $\mathrm{LH}$ decreased in prevalence from $11.3 \%$ in the youngest group to $5.4 \%$ in the $65-74$-year-old group and increased slightly to $6.1 \%$ in the oldest category $(P<0.05)$. Within each age category (except for subjects under the age of 44 years), the prevalence of LH was higher among men than among women.

Education. Handedness was not related to levels of education among men (Table 2). However women with $\geqslant 12$ years of education were more likely to be left-handed than women who did not complete high school. The ORs were $1.7(95 \% \mathrm{Cl}, 1.1-2.7)$ for 12 years of education, $1.4(95 \%$ $\mathrm{CI}, 0.8-2.3)$ for women with some college, and $2.0(95 \%$ CI, 1.2-3.3) for college graduates.

Race. Among Blacks, the OR for LH were $1.2(95 \%$ $\mathrm{CI}, 0.9-1.6)$ among men and $1.1(95 \% \mathrm{CI}, 0.7-1.7)$ in women relative to whites (Table 3 ).

Marital status. Comparing ever-married to never-married patients (Table 3 ), the ORs for $\mathrm{LH}$ were $0.7(95 \% \mathrm{CI}$, 0.5-0.9) among men and 0.5 (95\% CI, 0.3-0.9) among women.

\section{Effects of Lifestyle Factors}

Smoking. Among both men and women, cigarette smoking status was unrelated to LH (Table 4).

Alcohol use. Among men no differences were found in LH by levels of alcohol consumption (Table 4). Among women, there were no differences in LH for most levels of alcohol consumption. However, among self-reported alcoholics or binge drinkers as compared with never- or occasional drinkers, the OR for LH was 2.8 (95\% CI, 1.2-6.6).

Hormonal factors. Information on hormone use was collected from 447 (15\%) of the 3088 women. In postmenopausal women, the prevalence of $\mathrm{LH}$ in those who used estrogen replacement therapy (ERT) was $23.7 \%$, as compared with $4.3 \%$ in women who never used ERT (OR, $6.8 ; 95 \% \mathrm{CI}, 0.9-51.7$, Table 5). Handedness was not related to other hormonal and reproductive factors such as age of menarche, total years of reproductive life, menopausal status, number of full-term pregnancies, average menstrual cycle length, and the use of oral contraceptives.

Diagnosis. There were 194 women with breast cancer. As shown in Table 6, four $(2.1 \%)$ of these patients were left-handed, as compared with $189(6.8 \%)$ of 2887 other female patients (OR, $0.29 ; 95 \% \mathrm{CI}, 0.1-0.7)$. Of the men, (17.8\%) 27 of 152 patients admitted for fractures or injuries were $\mathrm{LH}$, compared with (7.7\%) 451 of 5883 admitted for other conditions (OR, 2.4; 95\% CI, 1.6-3.7). LH was not related to other diagnostic categories.

\section{DISCUSSION}

Several studies have documented a decrease in the percentage of $\mathrm{LH}$ with advancing age (1-6). The decreasing preva- 
TABLE 2. Prevalence of left-handedness by levels of education

\begin{tabular}{|c|c|c|c|c|}
\hline \multirow[b]{2}{*}{ Education } & \multicolumn{2}{|c|}{ Men } & \multicolumn{2}{|c|}{ Women } \\
\hline & $\begin{array}{c}\text { No. with } \\
\text { I.H/total }(\%)\end{array}$ & OR $(95 \% \mathrm{CI})$ & $\begin{array}{c}\text { No. with } \\
\text { LH/total }(\%)\end{array}$ & OR $(95 \%(x)$ \\
\hline$<12$ & $96 / 1241 \quad(7.7)$ & 1.0 & $25 / 529 \quad(4.7)$ & 1.2 \\
\hline 12 & $141 / 1753(8.0)$ & $1.0(0.8-1.4)$ & $71 / 1180(6.0)$ & $1.7(1.1-2.7)$ \\
\hline $13-15$ & $108 / 1197(9.0)$ & $1.1(0.8-1.4)$ & $39 / 702 \quad(5.6)$ & $1.4(0.8-2.3)$ \\
\hline$\geqslant 16$ & $132 / 1837(7.2)$ & $1.0(0.7-1.3)$ & $66 / 675 \quad(9.8)$ & $2.0(1.2-3.3)$ \\
\hline
\end{tabular}

TABLE 3. Relationships between left-handedness and race and marital status

\begin{tabular}{|c|c|c|c|c|}
\hline \multirow[b]{2}{*}{ Race } & \multicolumn{2}{|c|}{ Men } & \multicolumn{2}{|c|}{ Women } \\
\hline & $\begin{array}{c}\text { No. with } \\
\text { LH/total (\%) }\end{array}$ & OR (95\% CI) & $\begin{array}{c}\text { No. with } \\
\mathrm{LH} / \text { rotal }(\%)\end{array}$ & $\mathrm{CR}(95 \% \mathrm{CD})$ \\
\hline \multicolumn{5}{|l|}{ Race } \\
\hline White & $421 / 5360(7.9)$ & 1.0 & $179 / 2772(6.6)$ & 10 \\
\hline Black & $56 / 628 \quad(8.8)$ & $1.2(0.9-1.6)$ & $22 / 350 \quad(6.3)$ & $1.1(0.7-1.7)$ \\
\hline \multicolumn{5}{|l|}{ Marical starus } \\
\hline Never-married & $43 / 420 \quad(9.0)$ & 1.0 & $16 / 201 \quad(8.0)$ & 10 \\
\hline Ever-married & $435 / 5615(7.8)$ & $0.7(0.5-0.9)$ & $185 / 2702(6.4)$ & $0.5(0.3-0.9)$ \\
\hline
\end{tabular}

TABLE 4. Relationships between left-handedness and smoking and alcohol consumption

\begin{tabular}{|c|c|c|c|c|}
\hline \multirow[b]{2}{*}{ Behavior } & \multicolumn{2}{|c|}{ Men } & \multicolumn{2}{|c|}{ Women } \\
\hline & $\begin{array}{c}\text { No. with } \\
\mathrm{LH} / \text { total }(\%) \\
\end{array}$ & OR $(95 \% \mathrm{CI})$ & $\begin{array}{c}\text { No, with } \\
\text { LH/total (\%) }\end{array}$ & $O R(95 \%(\mathrm{Cl})$ \\
\hline \multicolumn{5}{|l|}{ Smoking } \\
\hline Never & $92 / 1136 \quad(8.1)$ & 1.0 & $69 / 1149 \quad(6.0)$ & $1 \ldots$ \\
\hline Former & $172 / 2024(8.5)$ & $1.0(0.8-1.2)$ & $69 / 1019 \quad(6.8)$ & $0.9(1.6-1.7)$ \\
\hline Current & $192 / 2553(7.5)$ & $1.0(0.8-1.3)$ & $63 / 420 \quad(6.9)$ & $0.7(0.7-1.2)$ \\
\hline \multicolumn{5}{|l|}{ Alcuhol use } \\
\hline Never & $223 / 2869(7.8)$ & 1.0 & $146 / 2449(6.0)$ & 1.3 \\
\hline$<301 / \mathrm{d}$ & $101 / 1270(8.0)$ & $1.0(0.8-1.3)$ & $38 / 406 \quad(9.4)$ & $1.6(1.1-2.3)$ \\
\hline $3-7 \mathrm{or} / \mathrm{d}$ & $71 / 886 \quad(8.0)$ & $1.0(0.8-1.3)$ & $7 / 140 \quad(5.0)$ & $0.7(0.3-1.6)$ \\
\hline$>70 z / \mathrm{d}$ & $61 / 669 \quad(8.4)$ & $1.0(0.8-1.4)$ & $4 / 50$ & $1.1(0.4-3.0)$ \\
\hline Alcoholic & $22 / 280 \quad(7.9)$ & $1.0(0.6-1.5)$ & $(16.2)$ & $2.8(1.2-6.6)$ \\
\hline
\end{tabular}

lence of LH in older individuals in our study is consistent with these reports. Some data show a large decline or absence of $\mathrm{LH}$ in individuals over the age of 75 years $(9,17)$, although we found that $\mathrm{LH}$ was still prevalent in these older age groups. In fact, the prevalence of $\mathrm{LH}$ was slightly higher among the oldest age group than among 65-74-year-old subjects. This finding could reflect a greater rate of hospital-

TABLE 5. Relationship between left-handedness and use of estrogen replacement therapy by postmenopausal women

\begin{tabular}{lll} 
& \multicolumn{1}{c}{ No. with } & \\
ERT use & LH/total (\%) & OR (95\% Cl) \\
\hline No & $1 / 19(5.3)$ & 1.0 \\
Yes & $115 / 438(26.7)$ & $6.9(0.9-52.8)$ \\
\hline
\end{tabular}

ization among older left-handed persons relative to older right-handed individuals, or could be due to sampling variability.

Men had a higher prevalence of $\mathrm{LH}$ than did women.

TABLE 6. Handedness and diagnostic category

\begin{tabular}{lll}
\hline \multicolumn{1}{c}{$\begin{array}{c}\text { No. wilh } \\
\text { LH/total (\%) }\end{array}$} & OR $(95 \% \mathrm{Cl})$ \\
\hline $\begin{array}{l}\text { Diagnosis } \\
\text { Women }\end{array}$ & & \\
$\quad$ Breast cancer & $4 / 194(2.1)$ & $0.3(0.1-0.7)$ \\
All others & $189 / 2887(6.8)$ & 1.0 \\
Men & & \\
Fracture & $27 / 152(17.8)$ & $2.4(1.6-3.7)$ \\
All Others & $451 / 5883(7.7)$ & 1.0 \\
\hline
\end{tabular}


Although some reports showed no gender differences in handedness, when differences are observed there is always a greater proportion of men with $\mathrm{LH}(1)$. The reasons for this difference are unclear but may reflect greater socialization pressures on females than on males (1).

Although hand use was unrelated to level of education among men, $\mathrm{LH}$ was more common in women with more then 12 years of formal education as compared with women who never earned a high school diploma. This finding is inconsistent with some literature suggesting that $\mathrm{LH}$ is more common in persons with low reading proficiency or cognitive disorders (1).

There is conflicting evidence as to whether handedness is weakly related to sexual preference $(20,21)$. We used the subjects' marital status as a crude proxy for sexual preference. After adjustment for age, the odds of LH was significantly higher among never-married men and women than among those who had married. These results are suggestive of samesex preference among $\mathrm{LH}$ individuals, although no firm conclusions can be drawn from this data.

The similar prevalence of $\mathrm{LH}$ among blacks and whites does not appear to be consistent with findings that ranked handedness in 16 countries. Porac and Coren (3) found that six of the seven samples with LH prevalence of $\leqslant 10 \%$ were in Caucasian populations, while eight of nine samples where the prevalence $\mathrm{LH}$ was $>10 \%$ were in black (Sierra Leone and Congo) and other non-Caucasian populations (3). It is not known whether these international differences are due to biological or cultural factors or to a combination of these. Our findings suggest that the differences may be due predominantly to cultural factors.

There was no relation between $\mathrm{LH}$ and smoking in our population. LH was also unrelated to alcohol consumption in men. However, a much higher proportion of women who identified themselves as binge drinkers or alcoholics were $\mathrm{LH}$ relative to women who reported that they infrequently or never drank alcohol. In a review of the literature, I larris found that more right-handed than left-handed women abstain from drinking alcohol (22). Other studies also suggest a higher prevalence of LH in alcoholic women (23).

The highest prevalence of $\mathrm{LH}$ was among men hospitalized for fractures. This finding is consistent with Coren's hypothesis that left-handed men are at higher risk for accidents than right-handed men, presumably because a highly technological society is designed for right-handed pcople. Several studies have found higher rates of injuries and fractures in left-handed men (24-26). In one study $18.2 \%$ of 55 hospitalized patients with traumatic brain injuries were more likely to have left-handed preference as compared with $10 \%$ in the general population $(P<0.01)$ (27). All the $\mathrm{LH}$ patients were motor vehicle drivers and were injured in automobile accidents. In contrast, another study found no differences in traffic accidents by handedness (28). A large Swedish study, significant in that it did not find overall mortality differences by handedness, did find a trend toward increase motor vehicle accident deaths among left-handed men (14).

We found a low prevalence of left-handedness among women with breast cancer $(2.1 \% ; P<.01)$, which is consistent with other findings (29). We can only speculate on the reasons for this. It is well established that later age at menarche and earlier age at menopause is associated with a decreased risk of breast cancer (30). Using a small sample from data collected from the National Health and Nutrition and Examination Survey (NHANES), Leidy (31) showed a significantly younger mean age of natural menopause among left-handed women ( 42.3 years) than right-handed women (47.3 years). A lower mean age at menopause among lefthanded women was also noted in a study of 182 women (32). However, another study of $>10,000$ women did not confirm these observations in multivariate analysis (33). Similarly, LH was not associated with age at menarche and age at menopause in our population, although there were too few $\mathrm{LH}$ women with breast cancer to examine differences in age at menopause between left- and right-handed women with breast cancer. There was a sevenfold but nonsignificant risk of LH associated with ERT use. ERT has has been found to promote the development of breast cancer in some studies but not in others $(34,35)$. It is unclear why left-handed women should use ERT more than right-handed women. Perhaps left-handed women are more prone to postmenopausal symptoms. In any case, the higher rate of use of ERT by women with LH suggests a higher risk of breast cancer in left-handed women, which contradicts our findings of a nonsignificant but lower risk.

In summary, this study showed a decreasing prevalence in $\mathrm{LH}$ with older age, which could reflect decreased practice of switching handedness among younger cohorts. A limitation of this study is the use of a single measure to determine dextrality or sinistrality. Studies suggest that learned changes in handedness occur only for writing. Left-handers who successfully switch to the right hand for writing continue to use their left hand for other behaviors such as brushing teeth or throwing a ball (5). Nevertheless, our data indirectly suggest that the effects of societal pressure on switching the writing hand does not appear to explain the lower prevalence of LII with advancing age. LH was more common among men admitted for fractures and injuries than among other hospitalized patients. The patients with fractures suffered from presumably non-life-threatening conditions, and therefore this finding would not account for the age-related differences in handedness (36). However, these findings are consistent with other reports indicating that $\mathrm{LH}$ is associated with injuries within the same age strata, especially at younger ages $(27,37)$. In terms of prevention, these findings suggest that handedness needs to be considered in the design and use of industrial equipment.

In order to determine the effects of accidents on reduced 
longevity among persons with $\mathrm{LH}$, it would be desirable to examine the rates of serious and fatal accidents and injuries by handedness. Persons with fatal injuries were obviously not included in this study, nor were persons whose age was younger than 21 years. However, if nonfatal accidents and injuries occur more often in individuals with $\mathrm{LH}$, this raises the very plausible hypothesis that fatal accidents are also more common in that group. This issue should be examined in future studies.

Alternatively, there is a large body of literature suggesting that LH is a consequence of birth stress and associated physiological trauma. Birth stress, genetic effects, and intrauterine hormones may reduce survival, possibly causing impaired immunity (3). In addition, LH is associated with more severe sleep apnea, which is also related to reduced survival (38).

There were no differences in handedness among female patients admitted for injuries. However, LH was found to occur less frequently in breast cancer patients than in women admitted for other types of cancer and for noncancerous conditions. 'Thus, if the reduced longevity hypothesis applies to women, it is not the result of increases in specific chronic diseases such as cancer.

This work was supported by U.S. Public Health Service Grants no. CA68384, C.A-32617, and CA-17613.

\section{REFERENCES}

1. Porac C, Coren S. Lateral Preferences and Human Behavior. New York; Springer-Verlag; 1981:40-43.

2. Fleminger JJ, Dalton R, Standage KF. Age as a factor in the handedness of adults. Neuropsychologia. 1977;15:471-473.

3. Coren S, Halpern DF. Do right-handers live longer? Nature. 1988; $333: 213$.

4. Halpern DF, Coren S. Handedness and life span. N Engl J Med. 1991;54:998.

5. Coren S, Halpern DF. LH: A marker for decreased survival fitness. Psychol Bull. 1991;109:90-106.

6. Rogersson PA. On the relationship between handedness and longevity. Soc Biol. 1993;40:283-287.

7. Brackenridge $C$ ]. Secular variations in handedness over ninety years. Neuropsychokgica. 1981;19:459-462.

8. Rothman K]. Left-handedness and life expectancy [letter]. N Engl J Med. 1991;325:1041.

9. Strang J. Left-handedness and life expectancy [letter]. New Engl J Med. 1901;325:1042

10. Kuhlemeier KV. Longevity and left-handedness. Am J Public Health. 1991;81:513.

11. Marks JS, Williamson DF. Left-handedness and life expectancy [letter]. N Engl ] Med. 1991;325:1042.

12. Wolf PA, D'Agastino RB, Cobb J. Left-handedness and life expectancy Hetter]. N Engl J Med. 1991;325:1042.

13. Salive ME, Guralnik JM, Glynn RJ. Am J Public Health. 1993; $83: 265-267$.
14. Person PG, Allebeck P. Do left-handers hav inmeaned mortality? Epidemiology. 1994;5:337-340.

15. Aggleton JP, Bland JM, Kentridge, RW, Neare N]. Handedness and longevity: Archival study of cricketeers. Fy Med I. 1994:309: $1681-1684$.

16. Cerhan JR, Folsom AR, Potter JD, Prinear RJ. Handedness and murtal ity risk in older women. Am J Epidemiol 1994 140368 374

17. Hugdahl K, Satz P, Mitrushina M, Miller EP. Lett handedness and old age: Do left-handers die earlier? Neuropsrahologia. 1993.

18. Wynder EL, Stellman SD. The comparative epileminlong of tobacco. related cancers. Cancer Res. 1977;37:4608 $46 \%$

19. Oldtield RC. The assessment and andyss of hembetnes: The Edin burgh inventury. Neuropsychologia. 19710907.13

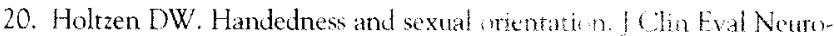
psych. 1994;16:702-712.

21. Danie) WP, Yeo RA. Handedness and sexual proterence; A reanalysis of data presented by Rosenstein and higler. Porcept Mor Skills. $1993 ; 76 \cdot 544-546$

22. Harris L]. Do left-handers die sooner than right-handers: Commentary on Coren and Halpern's (1991) "Left handedness: a morker for docreased survival fitness." Psychol Bull. $1993 ; 11+203-234$

23. MoNamara P, Blum D, O'Quinn $K$, Schahters Markers of cerebral lateralization and alcoholism. Percept Mot Sk:L 1994:79:1435-1440.

24. Coren S. Left-handedness and accident-related wiury risk Am I Public Health. 1989;79:1040-1041.

25. Hemenway D, Azrael DR, Rimm EB, Feskanich D, Willett WC. Risk factors for wrist fracture: Effect of age, cigarettes, alcohol, body weight, relative weight, and handedness on the risk for dival forearm fractures in men. Am ] Epidemiol. 1994;140:361 .367.

26. Graham CJ, Cleveland E. Left-handedness as an matury ractor in dolcicents. J Adolescent Health. 1905:16:50 ?

27. MacNiven E. Increased prevalence of left ham tedness in victims of head trauma. Brain Inj. 1994:8:457 462

28. Peters M, Perry R. No link between lett-handedness and maternal age and no elevated accident rate in left tanders. Neuropswchologia. $1991: 20: 1257-1259$

29. Olsson H, Ingvar C. Left handedness is uncommon in Freast cancer patients. Eur I Cancer. 1992;27:1694-1605

30. Rautalahti M, Alhanes D, Virtamo ], et al Lifetime menstrual activ ity -indicator of breast cancer risk. Eur Epideniol 199\%,9:17-25.

31. Leidy LE. Early age at menopause among left hatuded women. Ohster Gynecul. 1990;76:1111-1114.

32. Nikolova P, Stuyanov Z, Negrer Z. Functional tran symmetry, handed ness and menarcheal age. Int J Psychophysind 1994:18:213-215.

33. Pavia M, Hsieh CC, Ekbom A, Adami HO. Trichopolous D. Handedness, age at menarchs, and age at mempase. Obater Grocol. $1994 ; 83: 579-582$

34. Bernstein L, Ross RK, Henderson BE. Relationship of hormone use wo cancer risk. Monogr Nat Cancer Inst, 1992,12:137-147.

35. Khoo SK, Chick P. Sex steroid hormones and hreast cancer: Is there a link with oral contraceptives and bormone replacement therapy? Med J Aust. 1992;156:124-132

36. Halpern DF, Goren S. Left-handedness and life expectancy lletter| N Engl I Med. 1991;1042-1043.

37. Bhairo NH, Nijsten MW, van Dalen KC, ten [hus H]. Hand injuries in volleyball. Int ]. Sports Med. 1992;13:351-354

38. Hoffstein V, Chan CK, Slutsky AS. Handedness and step apnea. Chest 1993;103:1860-1862 